كارايى سن شكارگر Nesidiocoris tenuis Reuter (Hempitera, Miridae) در كنترل بيد

Tuta absoluta Meyrick (Lepidoptera: Gelechiidae) كوجه فرنكى

\author{
در شرايط گلخانه \\ بيمان نامور "** و شهرام فرخى \\ (تاريخ دريافت: 99/r/19 19؛ تاريخ يذيرش: 99/V/9 19)
}

جكيده

بيد گوجهفرنكى Tuta absoluta آفتى است كه از سال

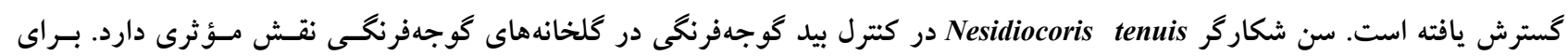

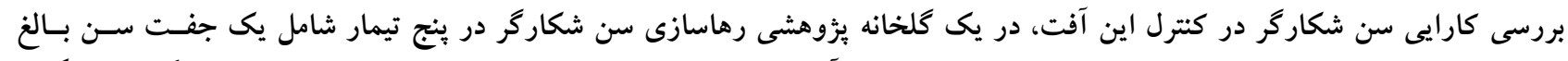

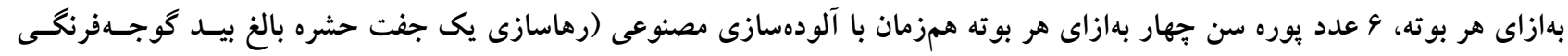

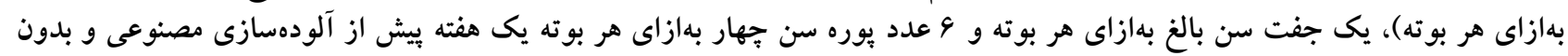

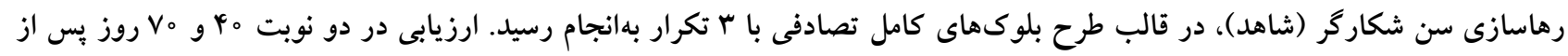

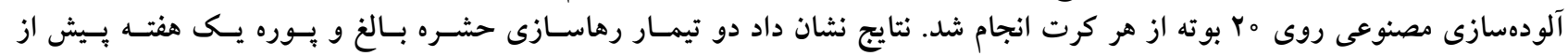

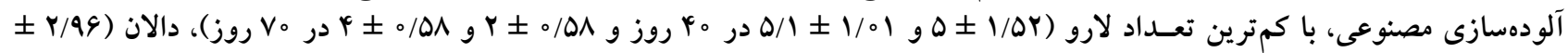

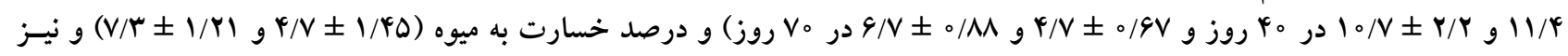

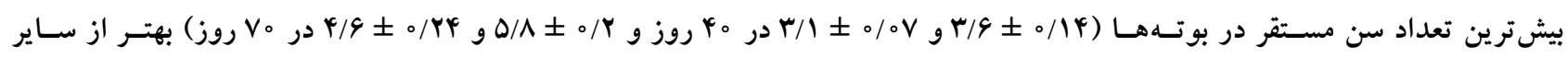

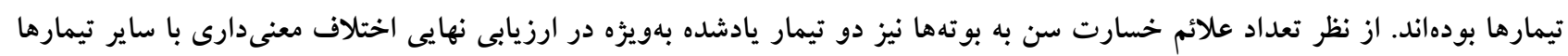

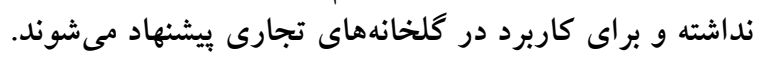
وازههاى كليدى: بروانه مينوز گوجهفرنخى، كارايى شكارگرى، كنترل بيولوزيك، جيرفت

(Gelechidae)

مقدمه

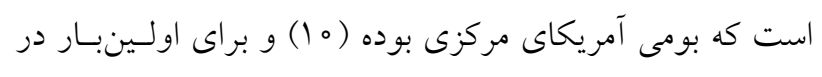

Tuta absoluta Meyrick (Lepidoptera: بيـ گوجسهفرنخـى ا. بخش تحقيقات كياهيزشكى، مركز تحقيقات و آموزش كشاورزى و منابع طبيعى جنوب كرمان، سازمان تحقيقات، آموزش و ترويج كثـاورزى، جيرفت r. بخش تحقيقات كنترل بيولوزيك، مؤسسه تحقيقات كياهيزشكى، سازمان تحقيقات، آموزش و ترويج كشاورزى، تهران

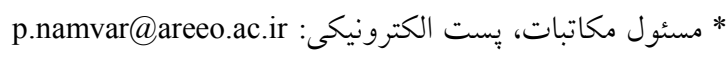




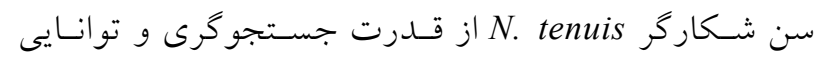

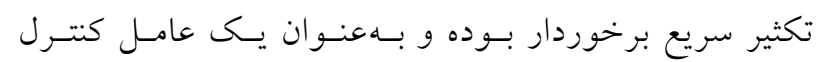

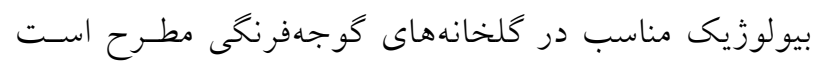

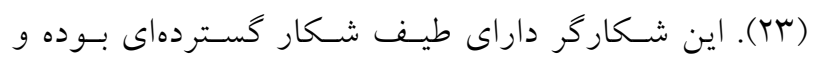

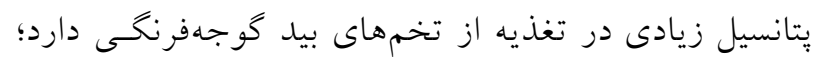
از اينرو در كشورهاى ارويايى بهصورت تجارى براى كنترل

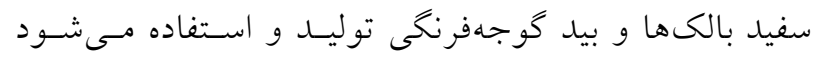

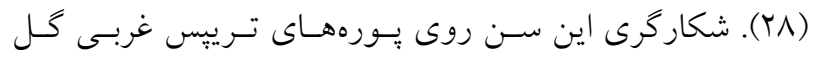
Frankliniella occidentalis Pergande مينوز Liriomyza trifolii Burgess در گوجهفرنكى، كنههاى تار عنكبوتى Tetranychus cinnabarinus Boisduval (r) و و نيـز

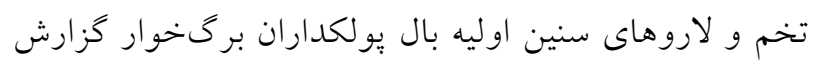

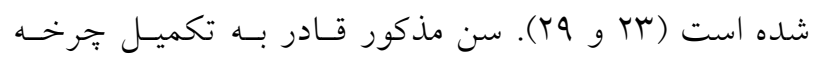

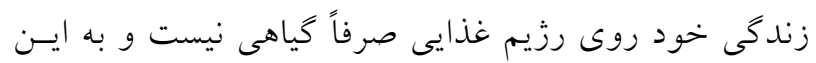

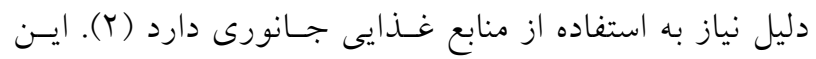

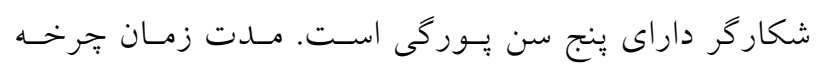

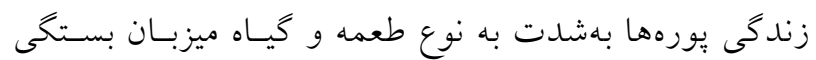

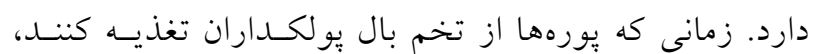

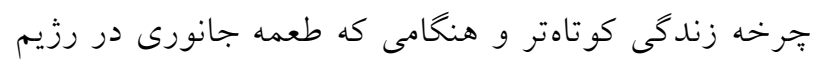

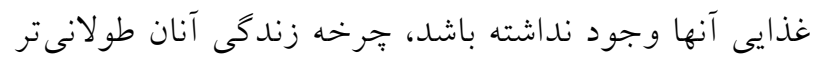
شده و كاهى تكميل نمىشود (T9).

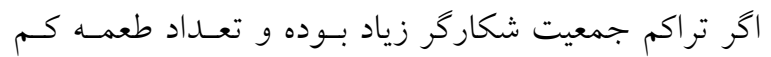
باشد، از شيره كياهى نيز تغذيه كـرده و بـهـ بـرى و سـاقه كيـاه

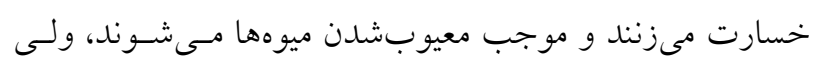

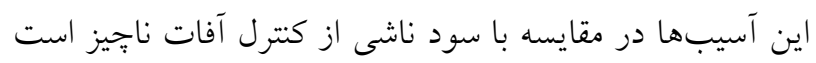

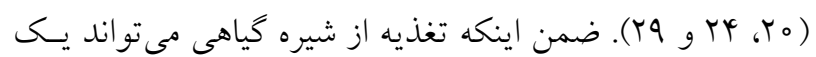

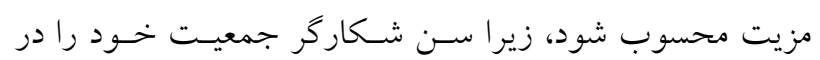

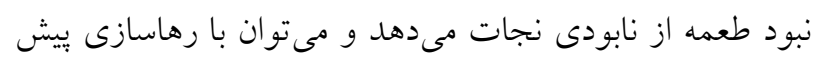

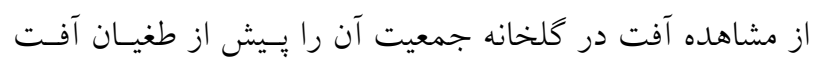
در سطح بالايى نخه داشت (9).

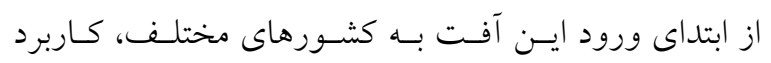

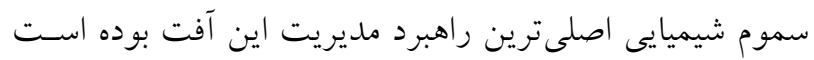

ايران در سال و>r| از شمال غرب كشـور و شهرسـتان اروميـهـ

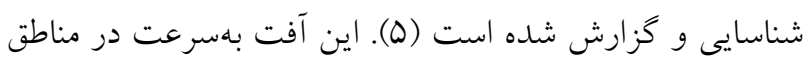

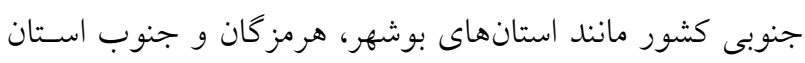

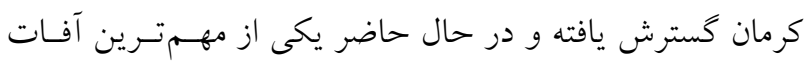

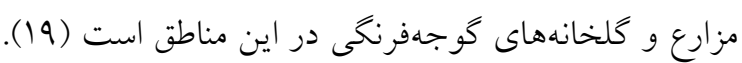

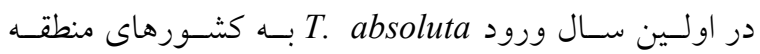
مديترانه، دو كونه سـن شـكارگر متعلـق بـهـ راسته ناجوربـالان

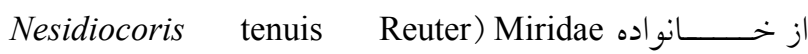
و Makcrolophus pygmaeus Rambur در حسال تغذيــه از

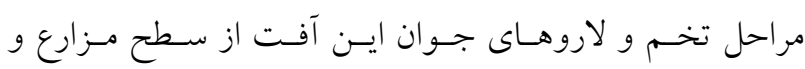

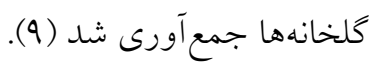

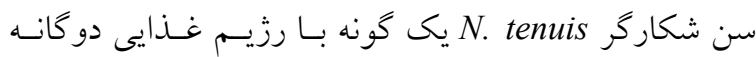
جانورخوار -کِياهخـوارى (Zoophytophagous) اسـت كـهـ البتـهـ

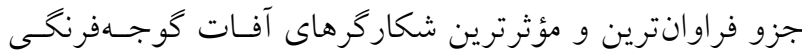

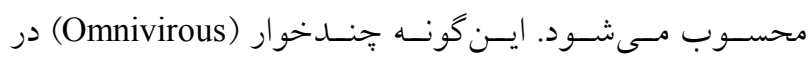

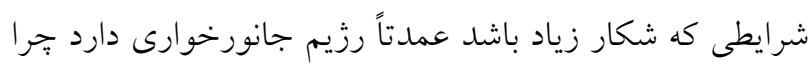

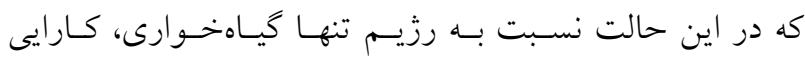
بيشترى دارد (Y) (به).

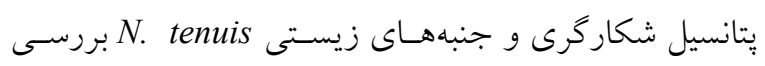

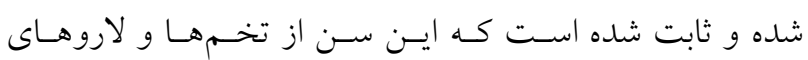
T. absoluta

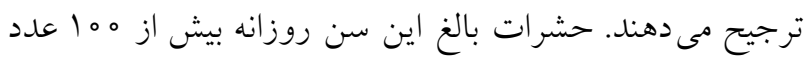

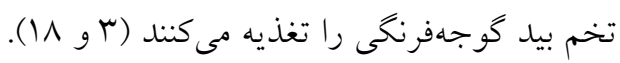

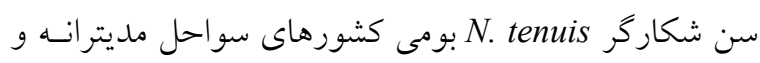

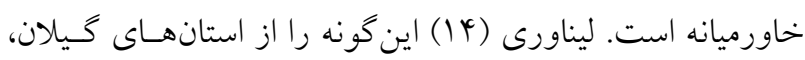

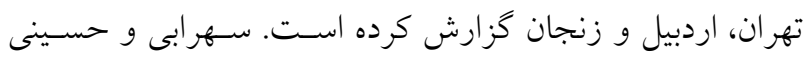
(TV)

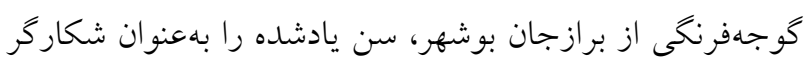

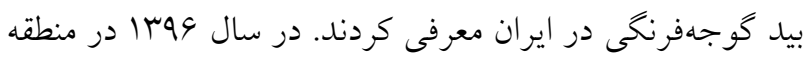
جيرفت واقع در جنوب استان كرمان نيز جمعيت زياد و فعاليت

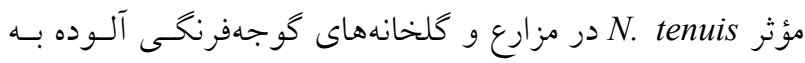
بيد كوجهفرنكى مشاهده و گزارش شد (بr). 
19:19 ساعت (روشنايى:تاريكى)، متتقل شده و سنهاى خـالص

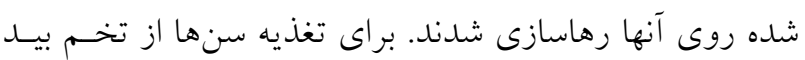

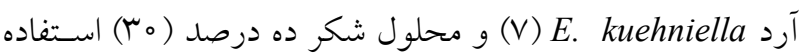

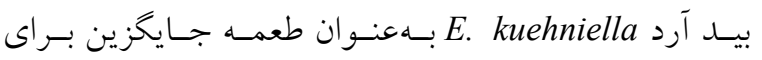
يـرورش سـنهـاى شـكارگر در انسـكتاريوم بخـش تحقيقـات

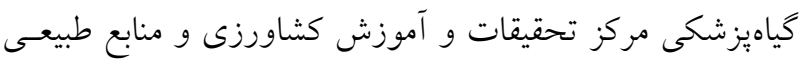

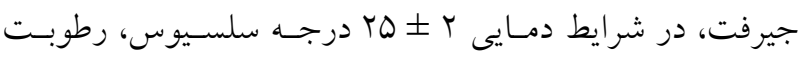
نسبى 10 د 90 درصد و دوره نـورى 19:19 (روشـنايى:تاريكى)

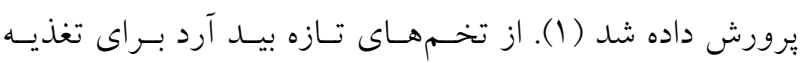

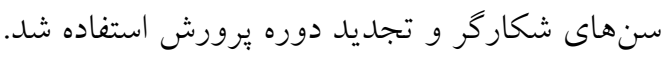

\section{جمع آورى و تكثير بيد گوجهفرنكى}

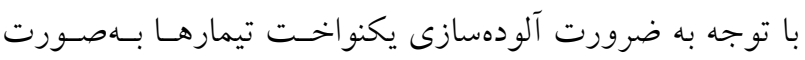

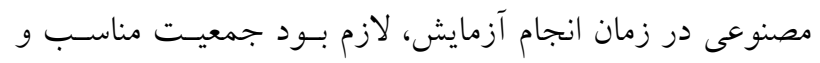

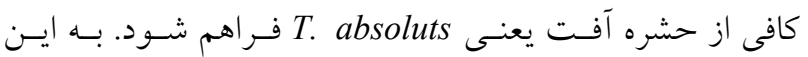

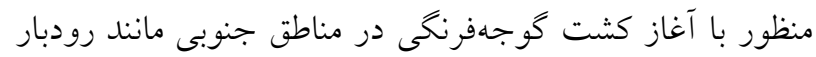

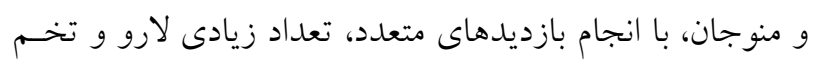

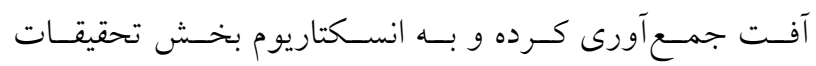

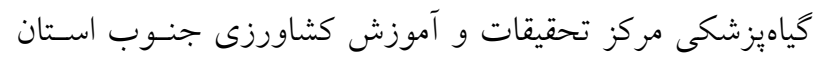
كرمان منتقل شدند.

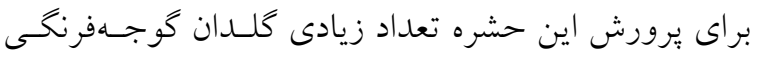

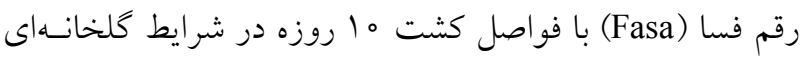

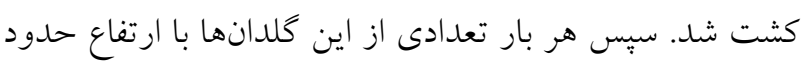

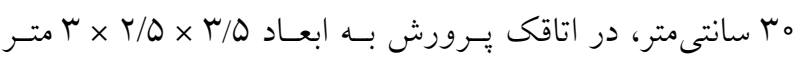

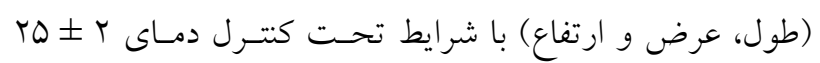

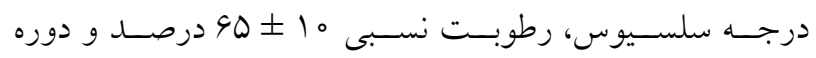

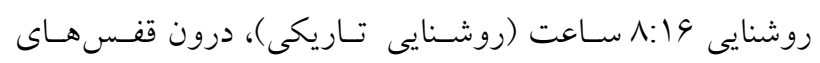
يرورش با حفاظ تورى به ابعاد

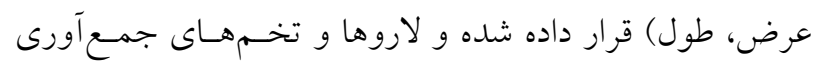

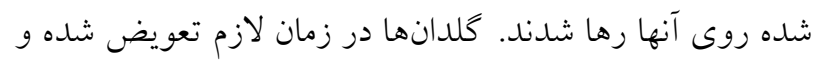
با ظهور حشرات بالغ در قفسها، از تعدادى اسـفنج آغشـته بــهـ (r) با و IV با اين وجود بهدليل فعاليت لاروهاى آفت در درون

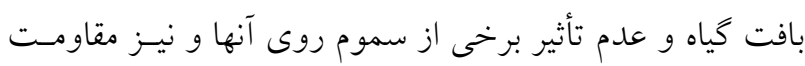

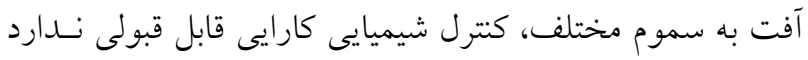

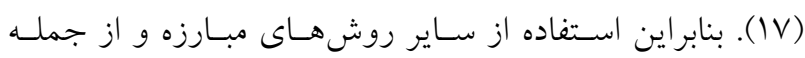

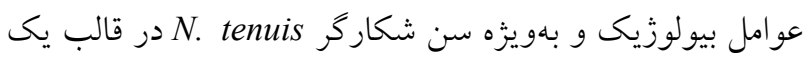

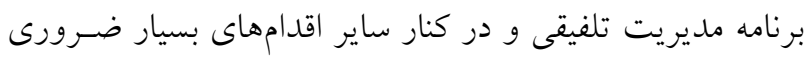

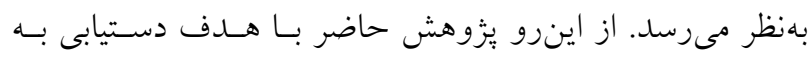

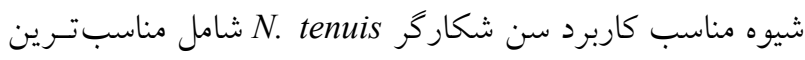

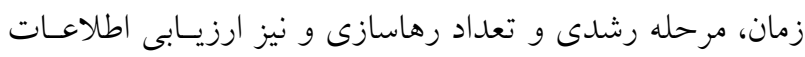

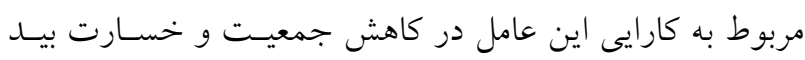

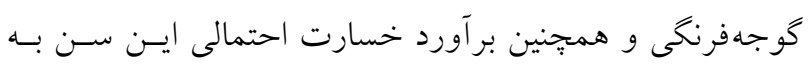

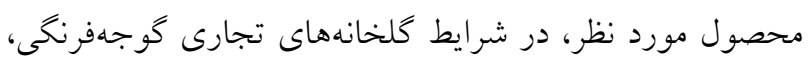
طر احى و اجرا شده است.

\section{مواد و روشها}

\section{يروش سن شكارگر N. tenuis و بيد آرد Efestia}

kuehniella

با توجه به حضور و فعاليت سن شكاركر در مزارع كوجهفرنكى

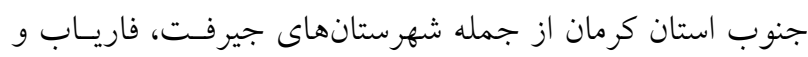

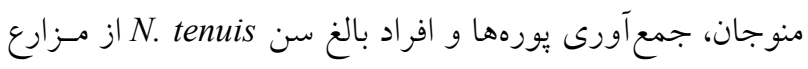

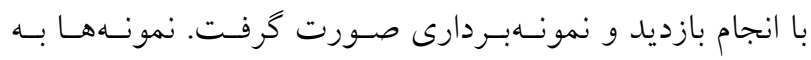

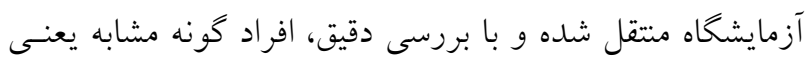

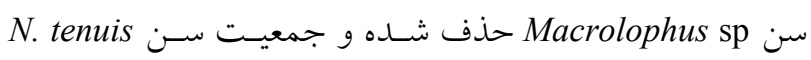

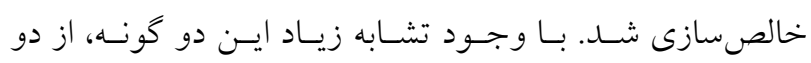

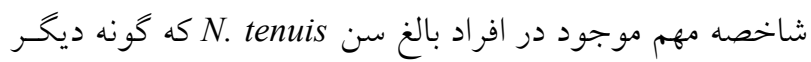

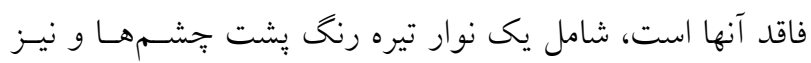

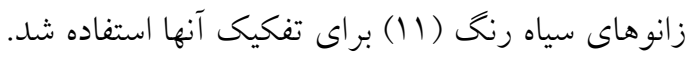

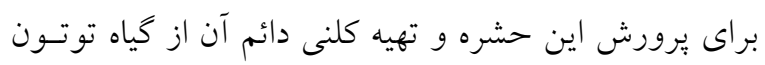

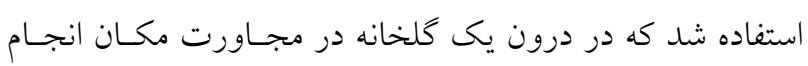

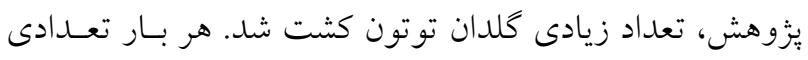

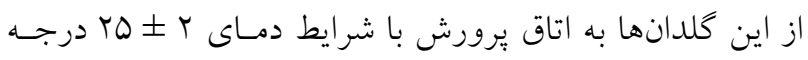

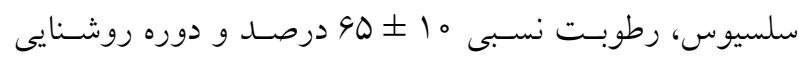


اشعه ماوراى بنفش (مشابه شرايط كلخانـهـــاى تجـارى منطقـهـ

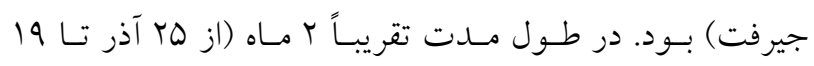

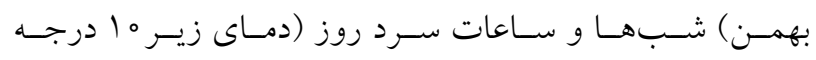

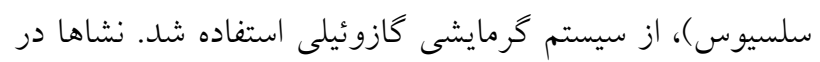

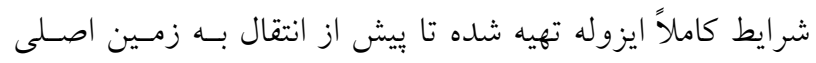

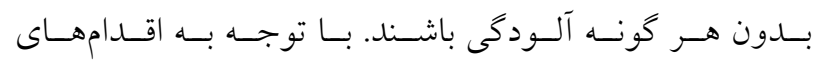

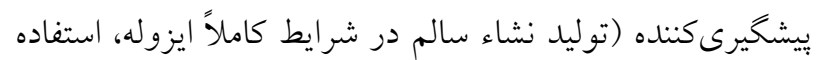

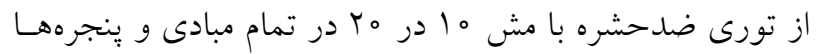

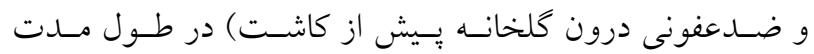
اجراى يزوهش جمعيت آفات بسيار كم بود و نيازى بـه اعمـال روشهاى كنتلى نبود.

تيمارها آزمايش در قالب طرح بلوكهاى كامل تصادفى با ب بلوى (هـر

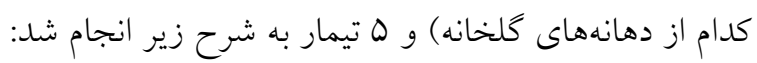


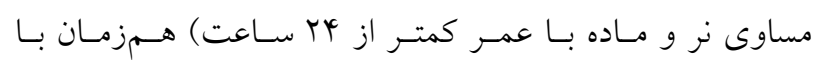

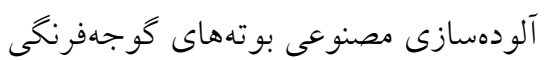

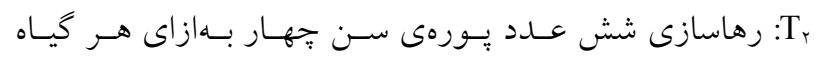

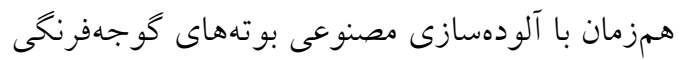


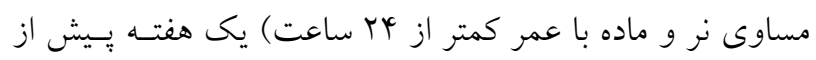

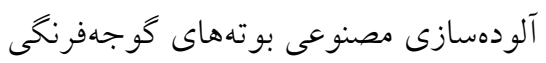


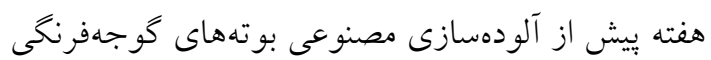

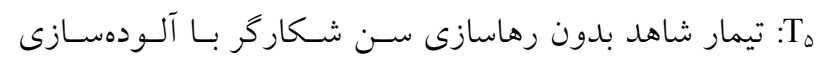
مصنوعى بوتههاى كوجهفرنخى

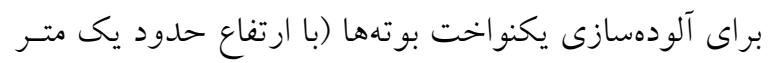

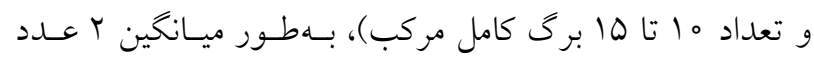
حشره كامل T. absoluta (مخلوطى از حشـرات نـــ و مـاده بـا طول عمر كمتر از YY ساعت) بهازاى هر بوته رهاسازى شد.
آب عسل ده درصد براى تغذيه حشـرات بـالغ اسـفاده شـدـ از حشرات بالغ موجود در كلنى براى آلودهسازى مصنوعى تيمارها (واحدهاى كلخانهاى گوجهفرنغى)، استفاده شد.

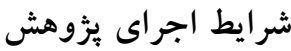

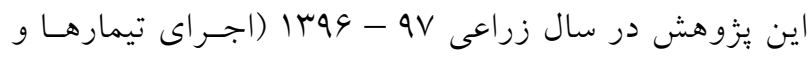

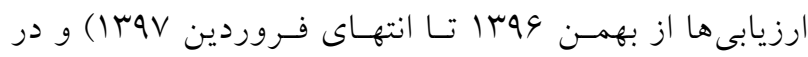

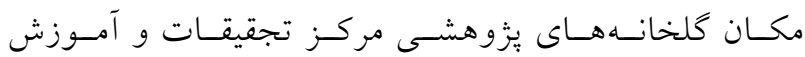
كشاورزى و منابع طبيعى جنـوب اسـتان كرمـان (بـا شــايط كاملاً مشابه كَلخانههاى تجـارى معمـول موجـود در منطقـهـ جيرفت از نظر سازه و امكانات) انجام شد. به اين منظور سه

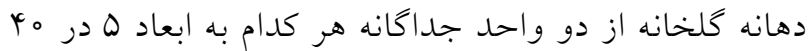
متر انتخاب شده و هر كدام به ه قسمت مساوى به مسـاحت

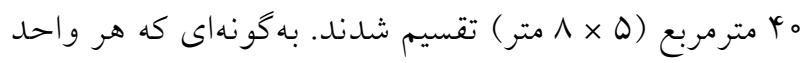

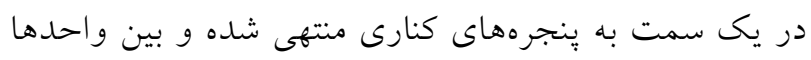

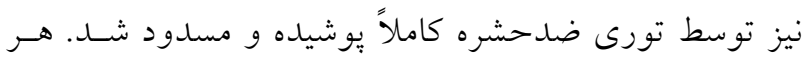

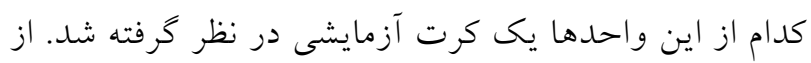

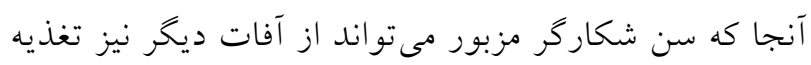
كند، براى جلو گيرى از ورود هر كونه آفت ديخر به كلخانسه

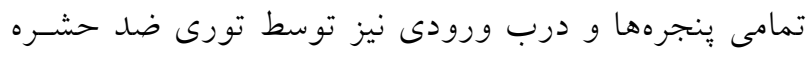

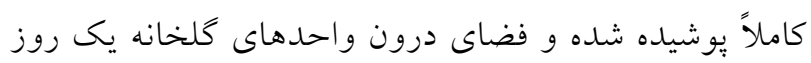

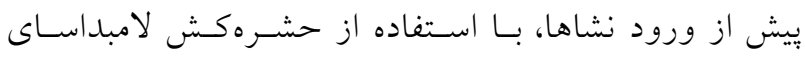
هالوترين به غلظت ه/ه در هزار، ضدعفـونى شــــ نشـاهاى

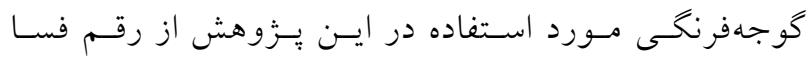

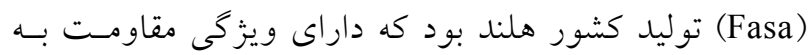

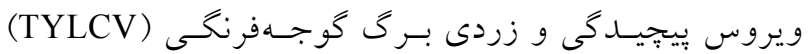
هستند. در هر واحد ه رديف كاشت 9 مترى با فاصله كاشت

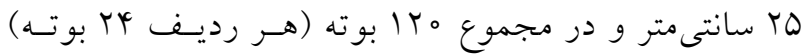
كشت شد. تغذيه و آبيارى بوتهها (سيستم تحت فشــار نـوارى) بـر

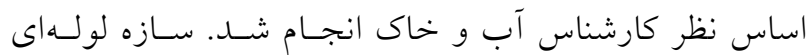

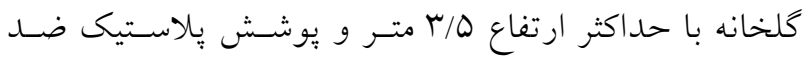


جدول 1. نتايج تجزيه واريانس تيمارهاى رهاسازى سن شكارگر Nesidiocoris tenuis در شرايط گلخانهاى

\begin{tabular}{|c|c|c|c|c|c|c|}
\hline CV (\%) & مقدار p & 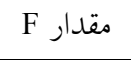 & ميانخين مربعات & درجه آزادى & منابع تغييرات & زمان ارزيابى \\
\hline $10 / 09$ & $\% / 0001$ & $M Y / I V^{*}$ & $r \Delta /{ }^{c} V$ & $r$ & تعداد لارو آفت & \multirow{4}{*}{ 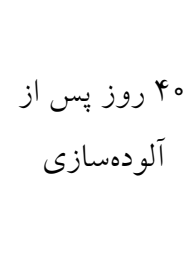 } \\
\hline $9 / 01$ & $0 / 0001$ & $99 / 1 r^{*}$ & $Y \circ T / V G$ & r & تعداد كل دالانها & \\
\hline$r V / D$ & 010099 & $V / \Upsilon \wedge^{*}$ & MV/TY & r & تعداد علائم خسارت سن & \\
\hline$\Lambda / \mu$ & $0 / 0001$ & lor/० $Y^{*}$ & $r / 9 \Lambda$ & r & تعداد سن مستقر در بوته & \\
\hline$r Q / K r$ & $\circ / 0001$ & $r q / r^{*}$ & MYY/gYt & 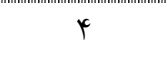 & تعداد لارو آفت & \multirow{5}{*}{ آلو دوز دوز بِ از } \\
\hline$I T / \Lambda$ & $\circ / 0001$ & $r Y Q / \circ Q^{*}$ & IYVN/०GV & r & تعداد كل دالانها & \\
\hline IV/GY & $\circ / 0009$ & $\mid r / T Y^{*}$ & lו & r & تعداد علائم خسارت سن & \\
\hline TS/AG & $\circ / 0001$ & $r q / r q^{*}$ & $100 N / 99 \mathrm{~V}$ & r & درصد ميوه خسارت ديده & \\
\hline $10 / 1 \mathrm{r}$ & $0 / 0001$ & $99 / 0 V^{*}$ & $9 / 994$ & r & تعداد سن مستقر در بوته & \\
\hline
\end{tabular}

نتايج تجزيه واريانس صفات مـورد ارزيسابى در رهاسـازى سـن

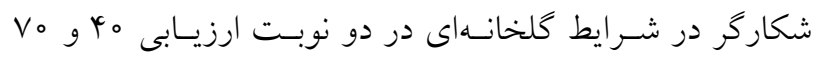
روز يّ از آلودهسازى، در جدول (1) ارائه شده است.

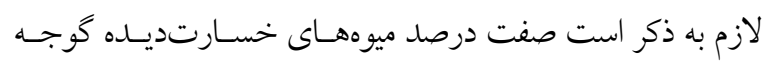

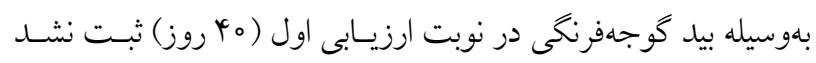

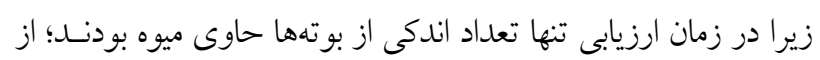

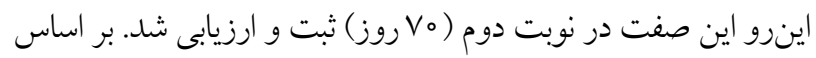

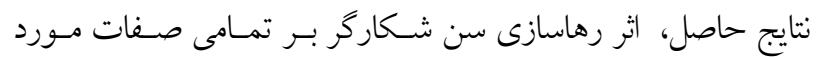

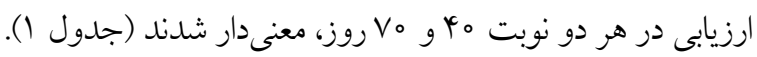

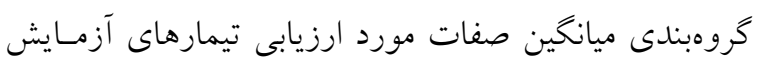

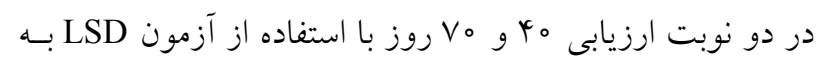

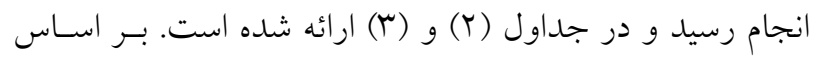
نتايج در تمامى صفات و در هر دو نوبـت ارزيسابى، بـين تيمـار

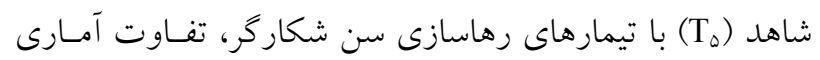

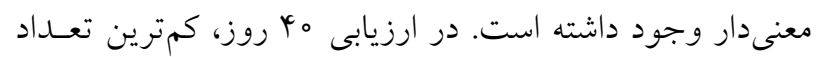

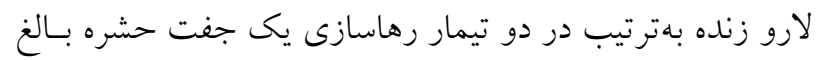

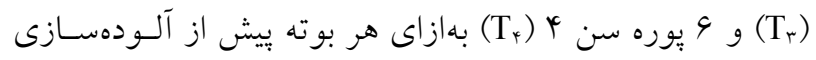

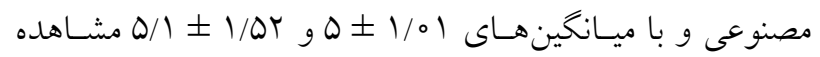

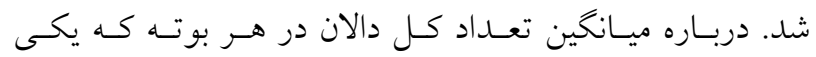

براى تعيين ميزان جمعيت و خسارت آفـت بـه محصـول و و نيـز

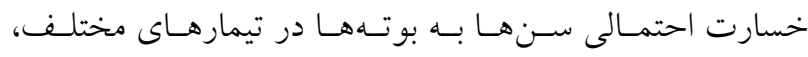

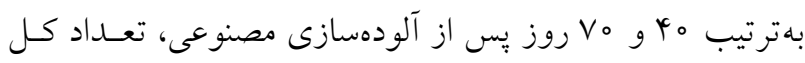

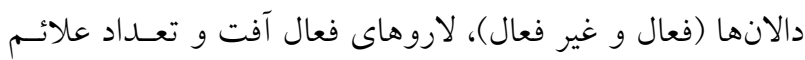

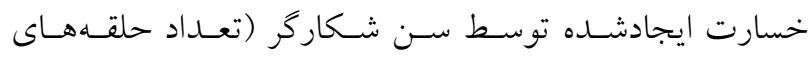

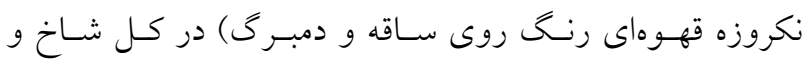

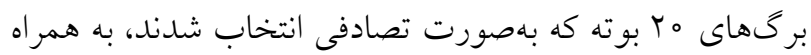

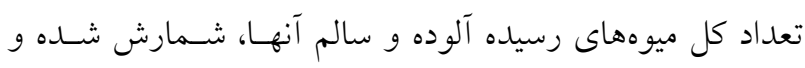

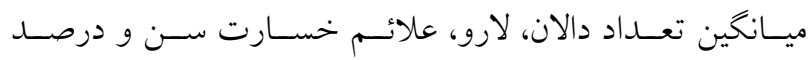

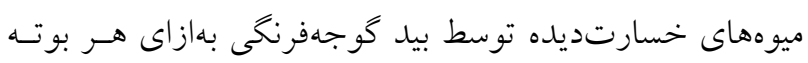

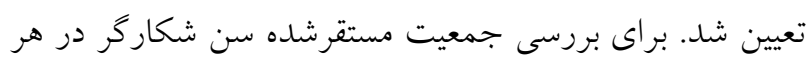

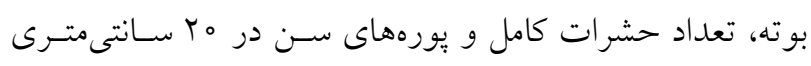

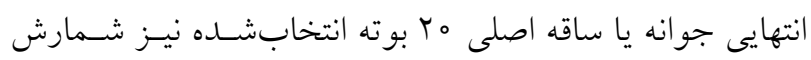

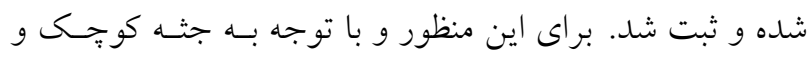

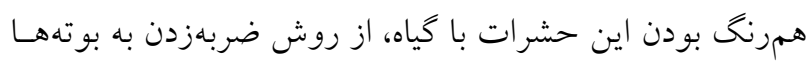
و بركها و شمارش حشرات روى سـينى سـفيدرنخ زيــر آنهـا

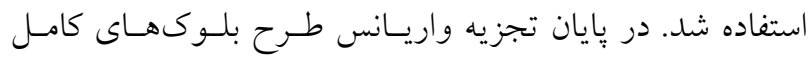

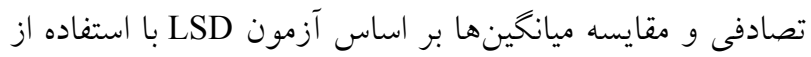

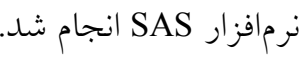


جدول r. گروهبندى ميانخين (土 خطاى استاندارد) تيمارهاى رهاسازى سن شكارگر Nesidiocoris tenuis

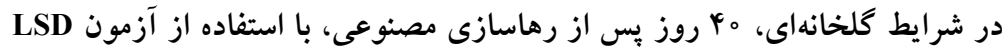

\begin{tabular}{|c|c|c|c|c|}
\hline تعداد سن در طول & تعداد علائم خسارت سن & تعداد كل دالان & تعداد لارو & تيمار \\
\hline$r / \Lambda \pm \circ / / V^{b}$ & $1 \circ / \mathrm{V} \pm 1 / 9 \mathrm{~V}^{\mathrm{ab}}$ & $1 N / V \pm 1 / V G b$ & $\wedge \pm \circ / \Delta \Lambda^{b}$ & $\mathrm{~T}_{1}$ \\
\hline$T / 4 \pm 0 / Y^{c} b$ & $|r / 4 \pm| / r \mid$ a & $19 \pm$ r/Dr b & $q \pm 0 / 0 r^{b}$ & $\mathrm{~T}_{r}$ \\
\hline$r / \varphi \pm 0 / / y^{a}$ & $q / 4 \pm \circ / \sqrt{ } q a b$ & $11 / 4 \pm r / 9 \varphi^{c}$ & $\Delta \pm 1 / \Delta Y^{c}$ & $\mathrm{~T}_{r}$ \\
\hline$r / \Lambda \pm \circ / \circ V^{b}$ & $V / 4 \pm 1 / 4 \Delta b$ & $|\circ / V \pm Y / Y|^{c}$ & $0 / 1 \pm 1 / 01^{c}$ & $\mathrm{~T}_{4}$ \\
\hline - & 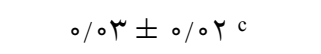 & $\mu / \mu \pm \Gamma / \Lambda \varphi^{q}$ a & $10 \pm \circ / \Delta \Lambda^{a}$ & $\mathrm{~T}_{\Delta}$ \\
\hline
\end{tabular}

جدول r. گروهبندى ميانگين (土 خطاى استاندارد) تيمارهاى رهاسازى سن شكارگر Nesidiocoris tenuis

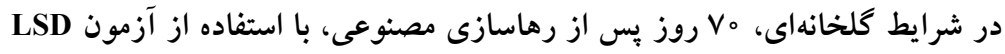

\begin{tabular}{|c|c|c|c|c|c|}
\hline درصد ميوه آلوده & تعداد سن در طول & تعداد علائم خسارت سن & تعداد كل دالان & تعداد لارو & 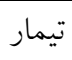 \\
\hline در هر بوته & مانتى متر ساقه & در هر بوته & در هر بوته & در هر بوته & \\
\hline$\Lambda \pm 1 / \Delta Y^{b}$ & $\varphi / r \pm 1$ bc & $1 \circ / N \pm \circ / M^{a}$ & $q / \vee \pm \circ / 1 q^{b}$ & $G / N \pm \circ / M b$ & $\mathrm{~T}_{1}$ \\
\hline $11 / \mathrm{V} \pm \circ / \Lambda^{\mathrm{b}}$ & $r / v \pm 0 / r q c$ & $q / \Gamma \pm|/ T|^{a}$ & $11 \pm 1 / \Delta \mu^{b}$ & $V / V \pm 0 / 9 V^{b}$ & $\mathrm{~T}_{r}$ \\
\hline$r / V \pm 1 / 4 \Delta b$ & $\Delta / \Lambda \pm \circ / Y)^{a}$ & $\mid r \pm \circ / \Delta \Lambda^{a}$ & $r / V \pm 0 / 9 V^{c}$ & $r \pm \circ / \mathrm{Q} \wedge \mathrm{b}$ & $\mathrm{T}_{r}$ \\
\hline$V / r \pm|/ r| b$ & $y / 9 \pm 0 / T y b$ & $11 \pm \circ / \Delta V^{a}$ & $G / N \pm \circ / \Lambda^{b c}$ & $r \pm \circ / \Delta \wedge \mathrm{b}$ & $\mathrm{T}_{\psi}$ \\
\hline$\Delta V / V \pm G / V Y^{c}$ a & - & $\circ / \circ \mu^{\prime} \pm \circ \%{ }^{b}$ & $G \Lambda / \Gamma \pm r / N Q$ a & 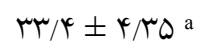 & $\mathrm{T}_{\Delta}$ \\
\hline
\end{tabular}

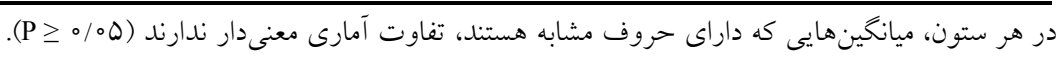

مصنوعى (T) ضمن تفاوت معنى دار با تيمار مـذكور، بـا سـاير تيمارهاى رهاسازى سن (T, T و T) تفاوت معنى دار نشان ندادند

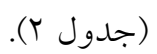

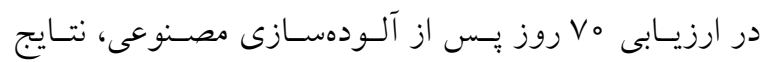

كروهبندى در صفات مختلف مقــارى تغييـر كـرد (جــدول م). بهطورى كه درباره تعداد لارو زنده تمامى تيمارهـاى رهاسـازى

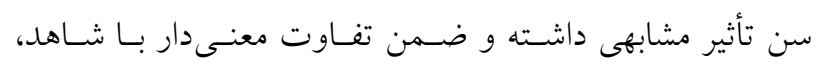
همخى با وجود تفاوت اندك در ميانخينها، در يك گروه آمارى قرار كرفتند. در مورد تعداد كل دالانها وضـعيت تقريبـاً مشـابه دوره يِيشين بوده و تيمار رهاسازى يك جفت حشره بالغ بهازاى

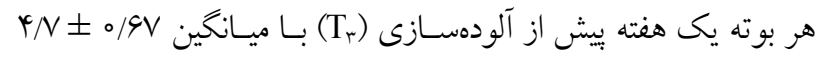
كمترين تعداد دالان در هر بوته را داشته و تيمار (T) با ميانخين
از شاخص هاى خسارت بيد كوجافرنخى است نيز به همين ترتيـب

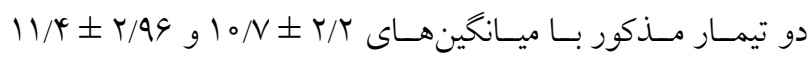

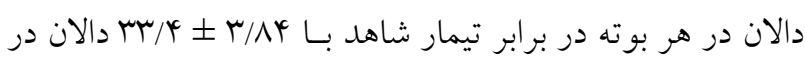
هر بوته، كمترين تيمار بوده و در يك گروه آمارى قرار گرفتنـد. درباره تعداد علائم خسارت سنها به بوتهها، بيشتـرين تعـداد

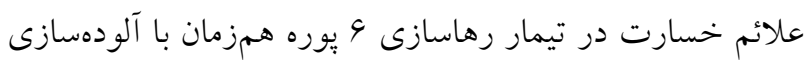

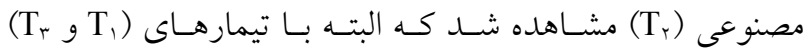
تفاوت معنى دار نداشت. همجنين بين تيمارهاى رهاسازى سـن،

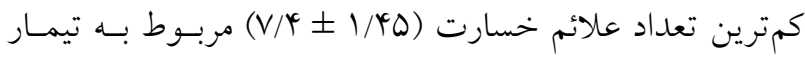
بود. درباره تعـداد سـن شـارگر مسـتقر در بوتسههـا نيـز بيشترين تعداد با ميانكين ץ/ به تيمار (Tr) بوده و تيمار رهاسازى צويوره بيش از آلودهسازى 
كاهش در تعداد دالانها روى برگها و در بايان هV روز (تـأثير

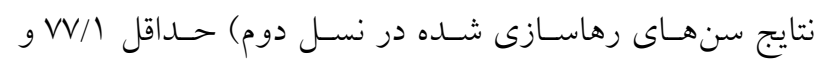

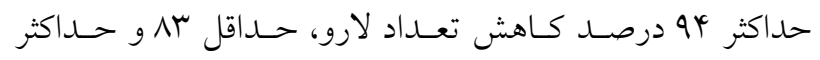

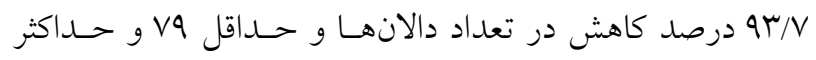
91/9 درصد كاهش در خسارت وارده به ميوهها نسبت به تيمسار شاهد مشاهده شد.

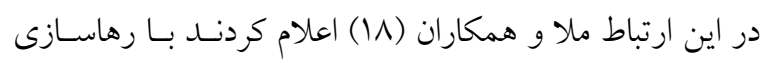

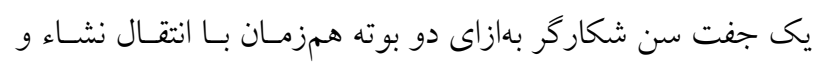

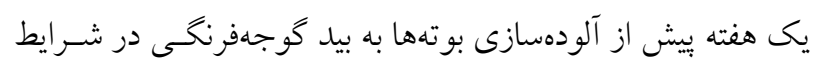

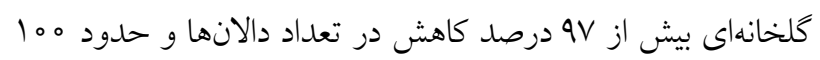

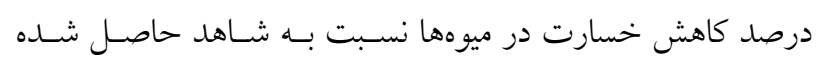

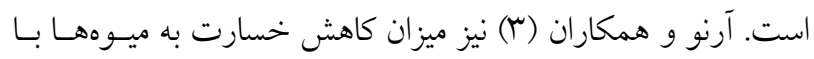

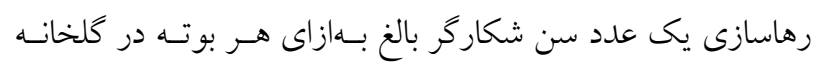

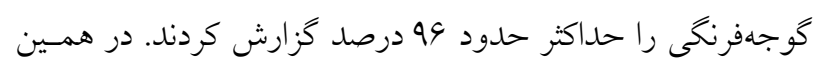

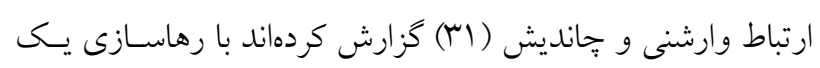

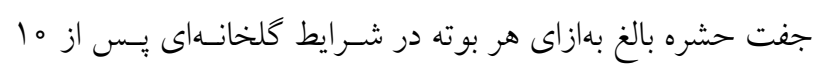

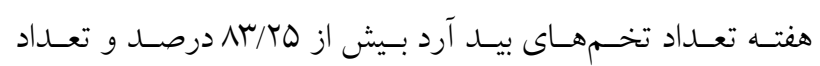

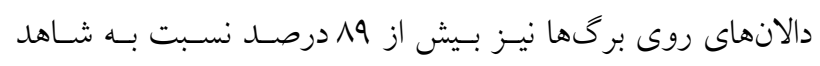

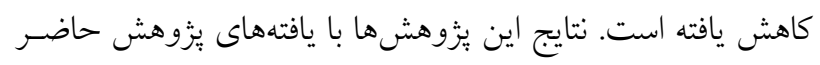

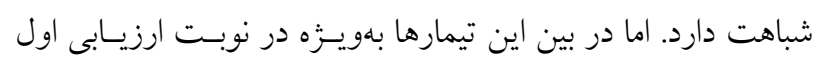

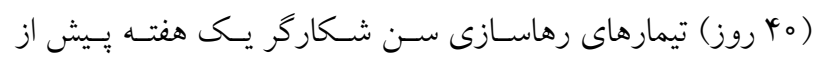

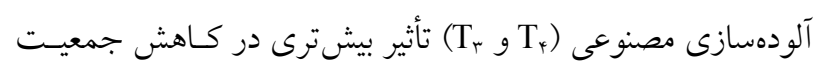

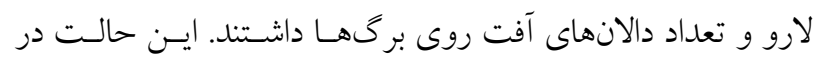

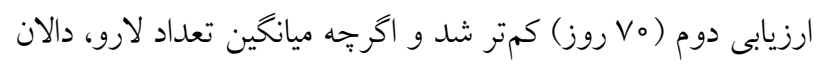

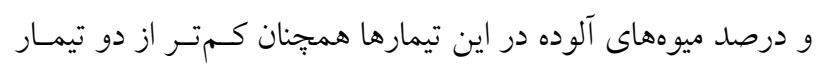

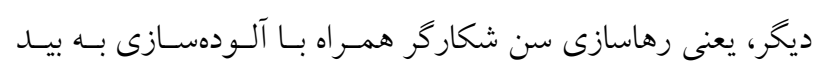

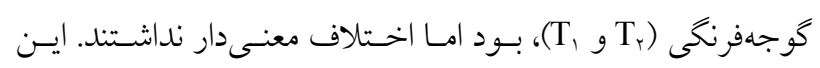

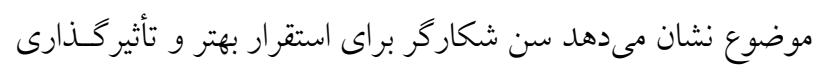

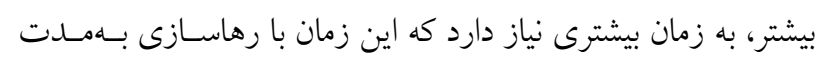

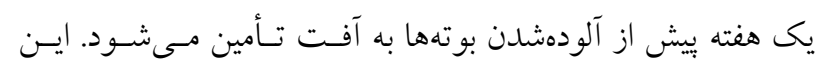

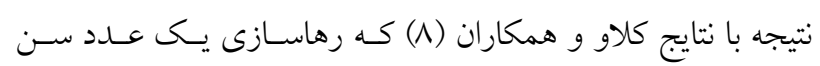

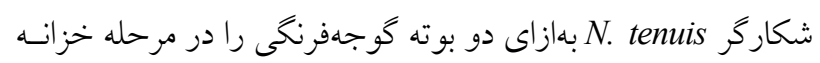

9/N D ض/M ساير تيمارهاى رهاسازى (T)

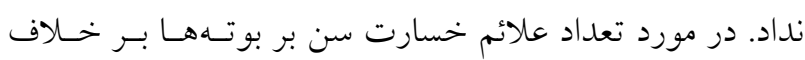

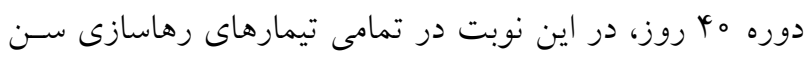

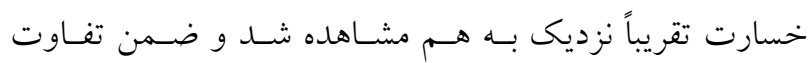

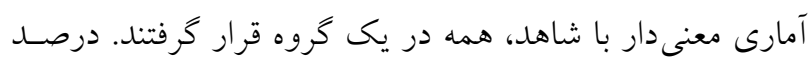

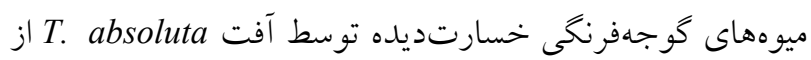

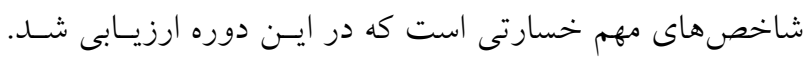

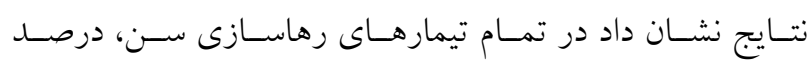

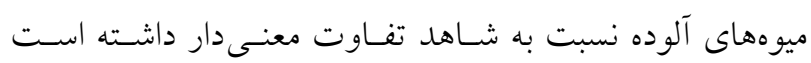

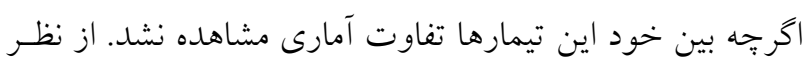
تعداد سن شكاركر مستقر در بوتهها، بيشترين تعداد باد با ميانكين

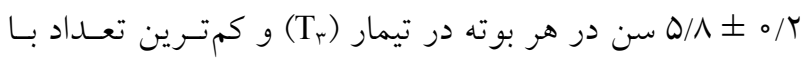
ميانخين (جدول r).

بر اساس نتايج حاصل تمامى تيمارها و در هر دو نوبت ارزيابى

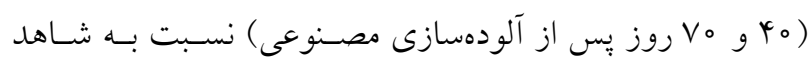

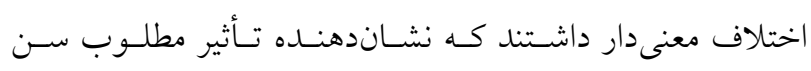

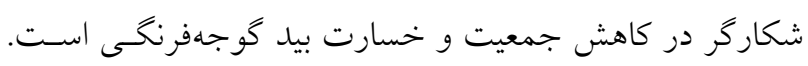

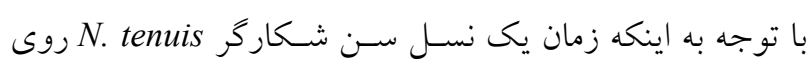

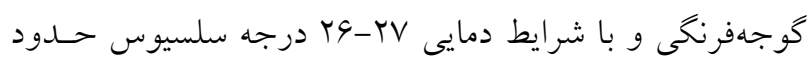

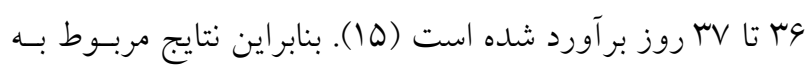

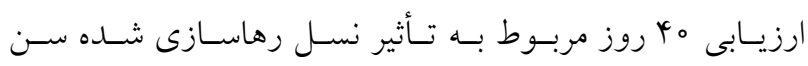

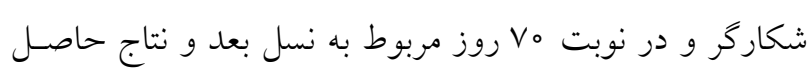

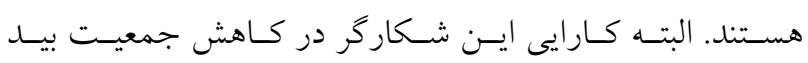

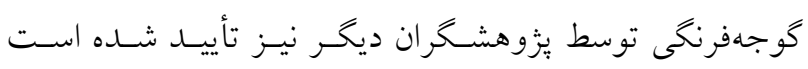

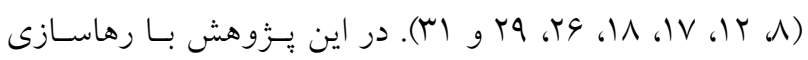

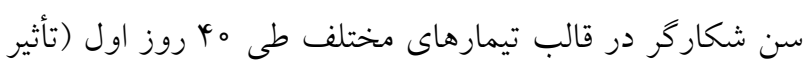

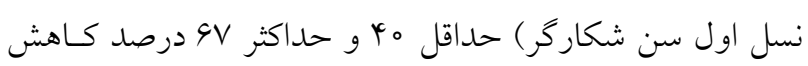

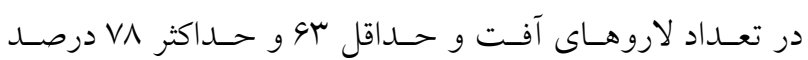




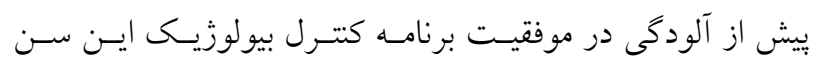

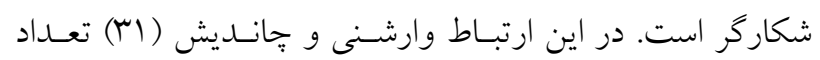

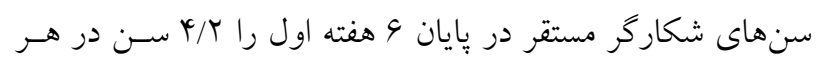

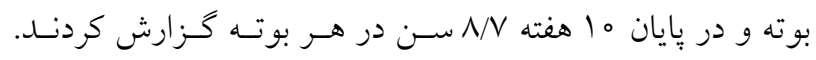

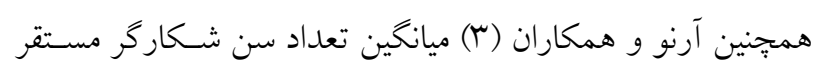

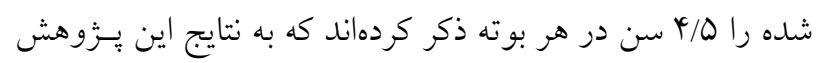
نزديك هستند. سانجز و همكاران (Y) كه شيوه رهاسازى سنهـ

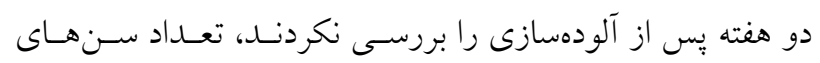

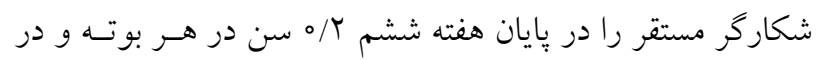

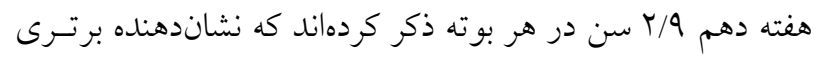

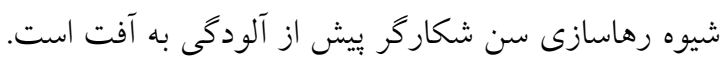

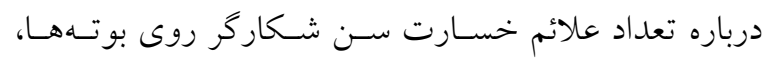

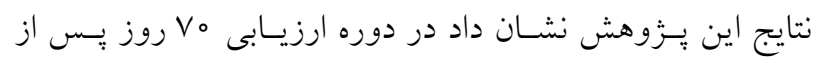

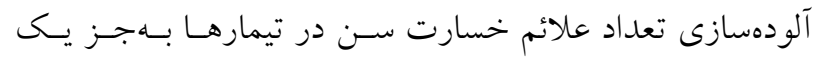

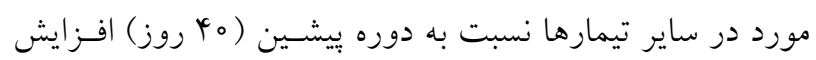

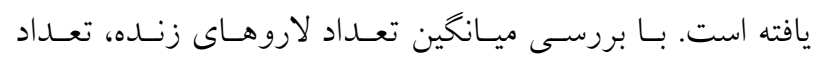

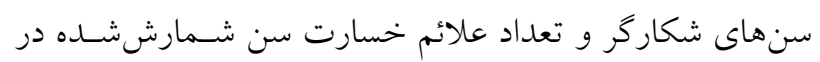

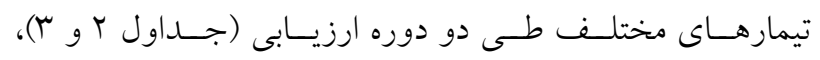

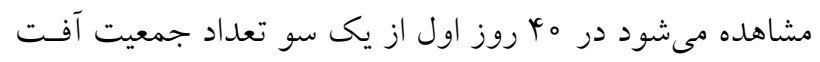

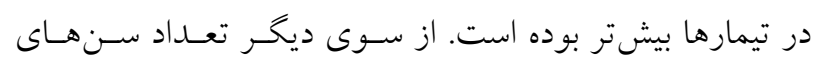

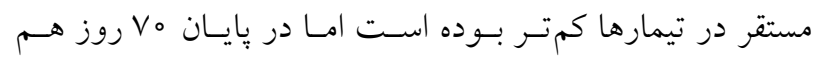

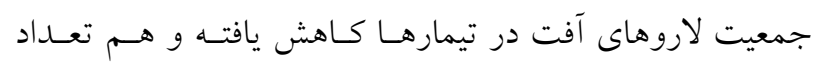
سنهاى مستقر افزايش يافته است؛ بنابراين افزايش تعداد علائم

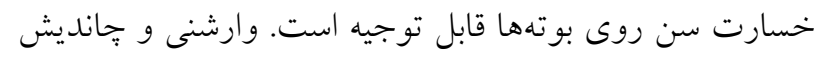

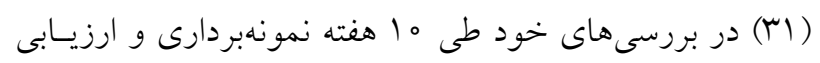

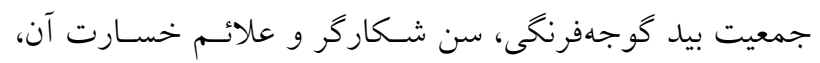

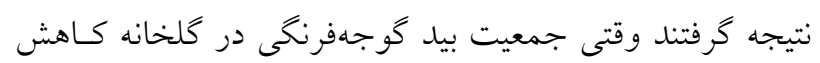

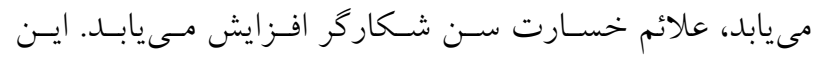

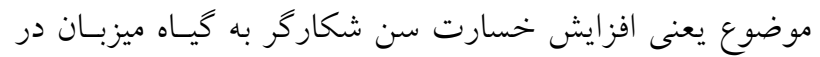

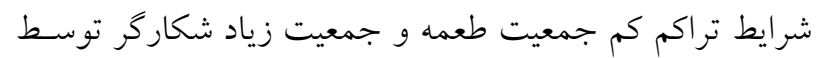
يزوهشخران ديخر نيز كزارش و تأييد شده است. اما آنها تصريح كردهاند كه اين آسيبها در مقايسه با سود ناشى از كتترل آفـات

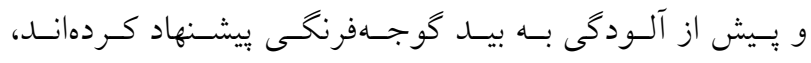

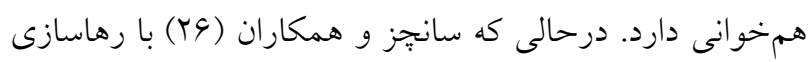

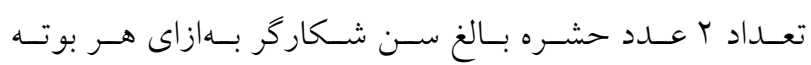
كوجهفرنخى دو هفته بس از آلودهسازى واحدهاى كُلخانه مورد

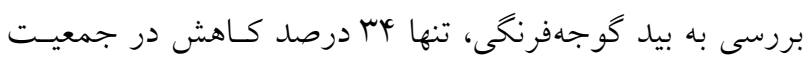

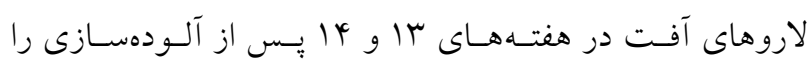

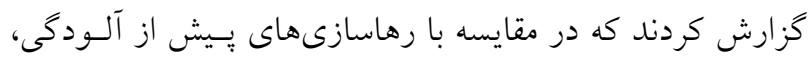
ميزان كارايى كمترى محسوب مى شودود.

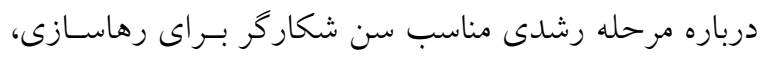

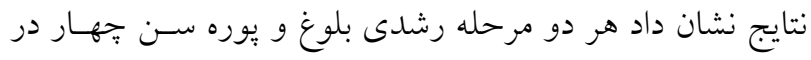

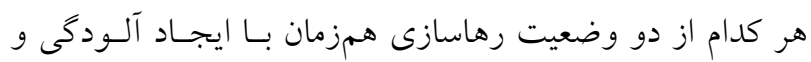
رهاسازى يك هفته ييش از آن، در كاهش تعداد لاروها، دالانها

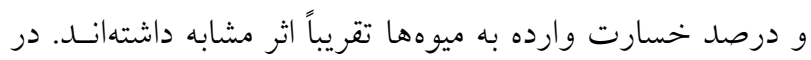

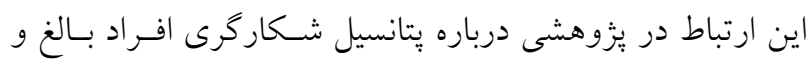

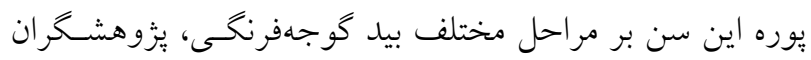

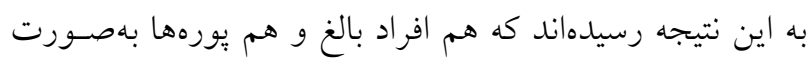

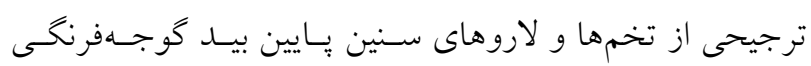

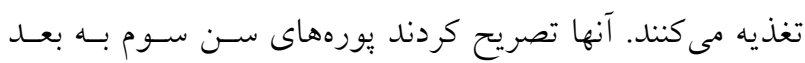

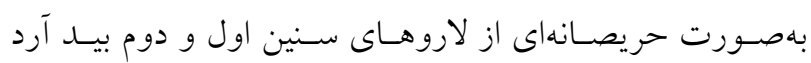

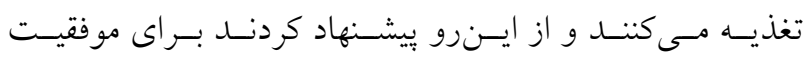

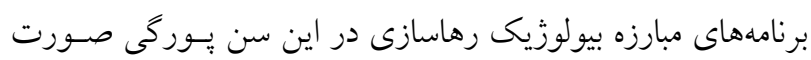

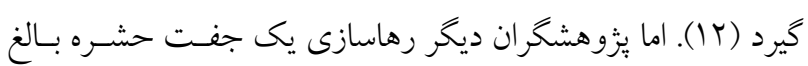

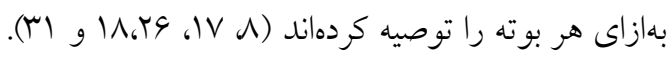

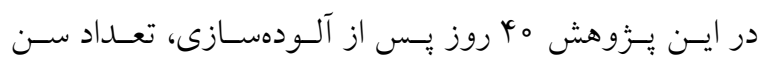

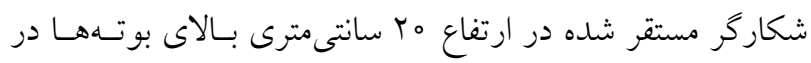

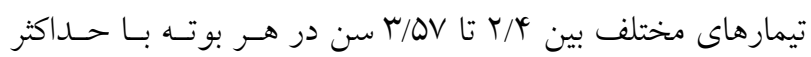

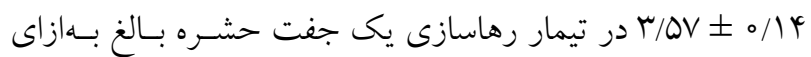

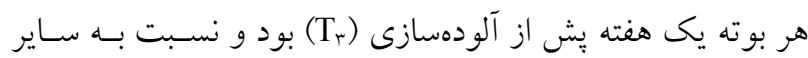

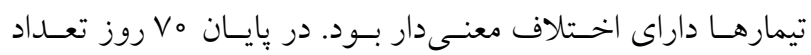

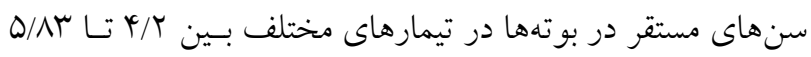

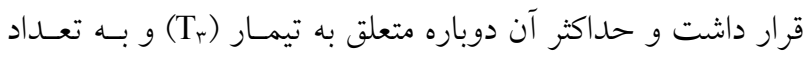
 


\section{نتيجه گيرى}

به عنوان يك نتيجه كيرى كاربردى بلويزه براى محيطهاى بسـته كشـت گياهـان از جملـه گلخانسههـا، مسىتـوان سـن شـكارگر N. tenuis را به تعداد يك جفت حشره بالغ (نر و مـاده) و يـا و عدد يوره سن ثَ بهازاى هر بوته همزمان با مشاهده اولين علائم خسارت آفت بيد گوجهفرنكى روى بركهاى بوتها و و يسيش از

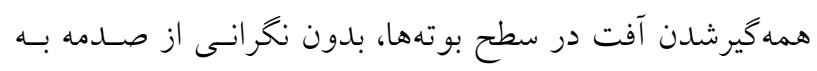
محصول اصلى، رهاسازى كرد.

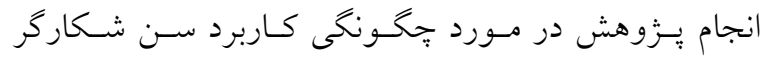
N. tenuis ديخر و نيز هماهنخ و ساز گار با روشهاى مديريت ساير آفات و بيمارىهاى كوجهفرنخى، در قالب يك برنامه مديريت تلفيقى مىتواند زمينهاى يزٔوهشى مناسـب در جهـت تكميـل

$$
\text { نتايج اين يزوهش باشد. }
$$

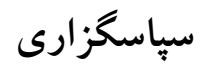

از سازمان جهاد كشاورزى جنوب كرمـان كـه بخـش مهمسى از اعتبارات مورد نياز اين يزوهش را تأمين كردند و نيـز از آقايـان دكتر جالال شيرازى و دكتر محمد على ضيائى مـدبونى بـهدليـل همكارى و مساعدت ايشان نهايت تشكر و سياس حاصل است.

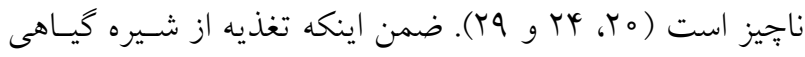
مىتواند يك مزيت محسوب شود، زيرا سن شـكارگر جمعيـت خود را در نبود طعمه از نابودى نجات مسىدهـد و مسىتـوان بـا

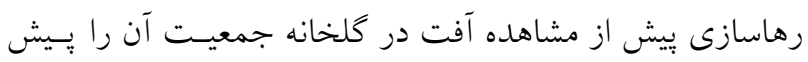
از طغيان آفت در سطح بالايى نخه داشت (9). نتايج اين يزوهش نشان داد برورش سن شكارگر روى گياه ميزبان و طعمه جايخزين و بلافاصله رهاسازى آن بـراى كنتـرل يرل يرول

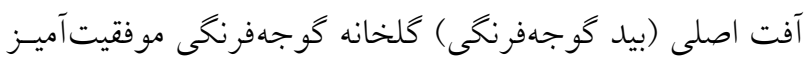

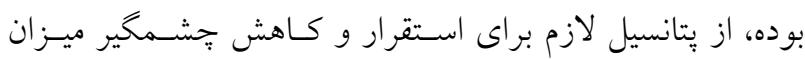

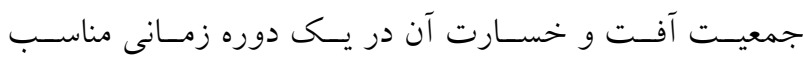
برخوردار بوده و تغذيه و خسارت آن به بوتههـاى كيـاه ميزبـان ناجِيز و قابل جششميوشى است. يزّوهشهاى اخير نشان داده كـــ سودمندى اين شكارگر در كنترل بيولوزيك آفات، بهويزه زمانى كه طعمه جانورى در اختيار داشته باشند بسـيار بيشـتر از ميـزان صدمهاى است كه در اثر تخمثذارى و يا تغذيه در بافـت گيـاه،

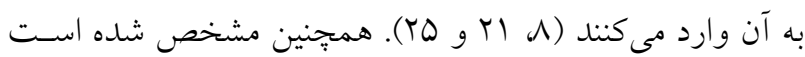
كه اين سنها در شرايط عدم وجــود طعمـه جـانورى قـادر بـه تكميـل نسـل خــود روى گيـاه ميزبـان نيسـتند و ايسن موضـوع نشاندهنده توانايى كم اين حشره در بقاى نسل در غياب طعمـهـ جانورى بوده كه خود يتانسيل كم آن در صدمه به كياه ميزبان را

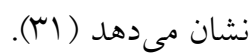

\section{منابع مورد استفاده}

1. Attaran, M.R. 1995. The effects of laboratory hosts on the biological characteristics of parasitoid wasps, Habrobracon hebetor MSc. Thesis. Tarbiat Modarres University. Tehran, Iran. (in Farsi)

2. Arno, J., C. Castane, J. Riudavets, J. Roig, and R. Gabarra. 2006. Characterization of damage to tomato plants produced by the zoophytophagous predator Nesidiocoris tenuis. IOBC/ WPRS Bull. 29: 249-254.

3. Arno, J., R. Sorribas, M. Prat, M. Montse, C. Pozo, D. Rodriguez, A. Garreta, A. Gomez and R. Gabarra. 2009. Tuta absoluta, a new pest in IPM tomatoes in the northeast of Spain. IOBC/WPRS Bull. 49: 203-208.

4. Arno, J., C. Castane, J. Riudavets and R. Gabarra. 2010. Risk of damage to tomato crops by the generalist zoophytophagous predator Nesidiocoris tenuis (Reuter) (Hem.: Miridae). Bull. Entomol. Res. 100: 105-115.

5. Baniameri, V. and A. Cheraghian. 2012. The first report and control strategies of Tuta absoluta in Iran. Bull. OEPP/EPPO 42(2): 322-324.

6. Castane, C., J. Arno, R. Gabarra and O. Alomar. 2011. Plant damage to vegetable crops by zoophytophagous mirid predators. Biol. Control 59(1): 22-29.

7. Castane, C. and R. Zapata. 2005. Rearing the predatory bug Macrolophus caliginosus on a meat-based diet. Biol. Control 34: 66-72.

8. Clavo, F.J., M.J. Lorente, P.A. Stansly and J.E. Belda. 2012. Preplant release of Nesidiocoris tenuis and 
supplementary tactics for control of Tuta absoluta and Bemisa tabaci in greenhouse tomato. Entomol. Exp. Appl. 143: 111-119.

9. Desneux, N., E. Wajnberg, K.A.G. Wyckhuys, G. Burgio, S. Arpaia, C.A. Narvaez-Vasquez, J. Gonzalez-Cabrera, D. Catalan Ruescas, E. Tabon, J. Frandon, J. Pizzol, C. Poncet, T. Cabello and A. Urbaneja. 2010. Biological invasion of european tomato crops by Tuta Absoluta: ecology, geographic expansion and prospects for biological control. J. Pest Sci. 83: 1-19.

10. García, M.F. and J.C. Espul. 1982. Bioecology of the tomato moth (Scrobipalpula absoluta) in Mendoza, Argentine Republic. Rev. de Investig. Agropecu 17:135-146.

11. Jacobson, R. 2019. Nesidiocoris tenuis biology and identification. Agriculture and Horticulture Development Board, Factsheet 03/17.

12. Lakshmi, S. E.T., T. Ramesh Babu, S.R. Koteswara Rao and G.S. Panduranga. 2018. Studies on predatory potential of Nesidiocoris Tenuis (Reuter) on Tuta Absoluta (Meyrick) (Lepidoptera:Gelechiidae). Int. J. Pure and Appl. Biosci. 6: 709-711.

13. Lietti, M.M.M., E. Botto and R.A. Alzogaray. 2005. Insecticide resistance in argentine populations of Tuta absoluta (Meyrick) (Lepidoptera: Gelechiidae). Neotrop. Entomol. 34: 113-119.

14. Linnavuori, R. 2007. Studies on the Miridae (Heteroptera) of Gilan and the adjacent provinces in Northern Iran. II. List of species. Acta Entomol. Musei Natl. Pragae 47: 17-56.

15. malkeshi, S.H., Mohaghegh, J., Talaei Hassanlouii, R. and Allahyari, H. 2018. A comparative study on demography of predatory bug, Nesidiocoris tenuis feeding on Ephestia kuehniella and Tuta absoluta eggs. Biol. Control Pest and Plant Dis. 2: 17-30. (in Farsi)

16. Megido, R.C., E. Haubruge and F.J. Verheggen. 2013. Pheromone-based management strategies to control the tomato leafminer, Tuta absoluta (Lepidoptera: Gelechiidae). A review. Biotechnol. Agron. Soc. Environ. 17: 475-482.

17. Molla, O., A. Biondi, M. Alonso-Valiente and A. Urbaneja. 2014. A comparative life history study of two mirid bugs preying on Tuta absoluta and Ephestia kuehniella eggs on tomato crops: implications for biological control. BioControl 59: 175-183.

18. Molla, O., H. Monton, P. Vanaclocha, F. Beitia and A. Urbaneja. 2009. Predation by the mirids Nesidiocoris tenuis and Macrolophus pygmaeus on the tomato borer Tuta absoluta. IOBC/WPRS Bull. 49: 209-214.

19. Namvar, P. and B. Gharaei. 2018. The most suitable type, height and location of Tuta absoluta pheromone traps and determination of its generations by degree day method. Plant Pest Res. 8: 29-42. (in Farsi)

20. Perdikis, D., A. Fantinou, N. Garantonakis, K.P. Pavlos, D. Maselou and S. Panagakis. 2009. Studies on the damage potential of the predator Nesidiocoris tenuis on tomato plants. Bull. Insectology 62: 41-46.

21. Perez-Hedo, M., P. Urbaneja-Bernat, J. Jaques, V. Flors and A. Urbaneja. 2015. Defensive plant responses induced by Nesidiocoris tenuis (Hem.: Miridae) on tomato plants. J. Pest Sci. 88: 543-554.

22. Riudavetes, J. and C. Castane. 1998. Identification and evaluation of native predators of Frankliniella Occidentalis (Thysanoptera: Thripidae) in the Mediterranean. Environ. Entomol. 27: 86-93.

23. Sanchez, J.A. 2008. Zoophytophagy in the plant bug Nesidiocoris tenuis. Agric. For. Entomol.10: 75-80.

24. Sanchez, J.A. and A. Lacasa. 2008. Impact of the Zoophytophagous Plant Bug Nesidiocoris Tenuis (Het.: Miridae) on Tomato Yield. J. Econ. Entomol. 101: 1864-1870.

25. Sanchez, J.A., A. Lacasa, J. Arno, C. Castane and O. Alomar. 2009. Life history parameters for Nesidiocoris Tenuis (Reuter) (Het., Miridae) under different temperature regimes. J. Appl. Entomol. 133: 125-132.

26. Sanchez, J.A., M. La-Spina and A. Lacasa. 2014. Numerical response of Nesidiocoris Tenuis (Hemiptera: Miridae) preying on Tuta Absoluta (Lepidoptera: Gelechiidae) in tomato crops. Eur. J. Entomol. 111: 387-395.

27. Sohrabi, F. and R. Hosseini. 2015. Nesidiocoris tenuis (Reuter) (Heteroptera: Miridae), a predatory species of the tomato leafminer, Tuta absoluta (Meyrick) (Lepidoptera: Gelechiidae) in Iran. J. Plant Prot. Res. 55: $322-323$.

28. Urbaneja, A., J. González-Cabrera, J. Arnó and R. Gabarra. 2012. Prospects for the biological control of Tuta absoluta in tomatoes of the Mediterranean basin. Pest Manag. Sci. 68: 1215-1222.

29. Urbaneja, A., G. Tapia and P.A. Stansly. 2005. Influence of host plant and prey availability on the developmental time and survival of Nesidiocoris tenuis Reuter (Het.: Miridae). Biocontrol Sci. Techn. 15: 513-518.

30. Urbaneja-Bernat, P., M. Alonso, A. Tena, K. Bolckmans and A. Urbaneja. 2013. Sugar as nutritional supplement for the zoophytophagous predator Nesidiocoris tenuis. Biocontrol 58: 57-64.

31. Varshney, R. and B. Chandish. 2017. Studies on evaluation of Nesidiocoris tenuis (Reuter) (Hemiptera: Miridae) preying on invasive insect pest Tuta absoluta (Meyrick) (Lepidoptera: Gelechiidae) and its damage to tomato plant. J. Biol. Control 31: DOI: 10.18311/jbc/2017/15751.

32. Xu, J.Y., X.S. Gu, W.H. Xu, Y.C. Bay and J.R. Chen. 2012. Predation of 5-instar Nesidiocoris tenuis on Tetranychus cinnabarinus. Shandong Agric. Sci. 5: 92-95.

33. Ziaei Madbouni, M.A., M.A. Samih, P. Namvar and S. Ranjbar. 2017. Side effects of some pesticides on predator bug Nesidiocoris tenuis Reuter (Hemiptera: Miridae). Appl. Res. Plant Prot. 6: 71-82. (in Farsi) 


\title{
Efficiency of Nesidiocoris tenuis Reuter (Hempitera, Miridae) in Controlling Tuta absoluta Meyrick (Lepidoptera: Gelechiidae) in Tomato Greenhouses
}

\author{
P. Namvar*1 and S. Farrokhi²
}

(Received: 8 June 2020; Accepted: 30 September 2020)

\begin{abstract}
Tomato leaf miner, Tuta absoluta Meyrick, is a pest which entered Iran in 2010; it was spread rapidly in many areas including Jiroft, in the southern Kerman province. The predatory bug, Nesidiocoris tenuis Reuter (Hempitera, Miridae) is an effective biocontrol agent against T. absoluta in tomato greenhouses. To evaluate the efficiency of $N$. tenuis in controlling T. absoluta, the predator was released in five treatments including: one pair of adult predator per plant, 6 fourth stage nymphs per plant in the same time with the artificial pest release, one pair of adult predator per plant and 6 fourth stage nymphs per plant one week before artificial pest release and control (no predator). The experiments were done in a completely randomized block design with 3 replications. Evaluation was done on 40 and 70 days after the artificial pest release on 20 plants per plot which had been selected randomly. The results showed that the two treatments of predator release before pest release were significantly better than the others in reducing the number of larvae $\left(5 \pm 1.52,5.1 \pm 1.01\right.$ on $40^{\text {th }}$ day and $2 \pm 0.58,4 \pm 0.58$ on $70^{\text {th }}$ day $)$, mines $\left(11.4 \pm 2.96,10.7 \pm 2.2\right.$ on the $40^{\text {th }}$ day and $4.67 \pm 0.67,6.7 \pm 0.88$ on $70^{\text {th }}$ day) and the percent of the damaged fruit $(4.7 \pm 1.45$ and $7.3 \pm 1.21)$, as well as increasing the predator established on plants $\left(3.6 \pm 0.14,3.1 \pm 0.07\right.$ on the $40^{\text {th }}$ day and $5.8 \pm 0.2,4.6 \pm 0.24$ on the $70^{\text {th }}$ day). Moreover, these two mentioned treatments had no significant difference with the others in regard to the symptoms of $N$. tenuis damage in plants, especially in the final evaluation; so they could be recommended for use in commercial greenhouses.
\end{abstract}

Keywords: Biological control, Jiroft, Predatory efficiency, Tomato leaf miner moth.

1. Plant Protection Research Department, South Kerman Agricultural and Natural Resources Research and Education Center, AREEO

2. Biological Control Department, Iranian Research Institute of Plant Protection, AREEO, Tehran, Iran

* Corresponding Author, Email: p.namvar@areeo.ac.ir 